\title{
Elementos para la revisión crítica de la relación entre el derecho penal y la vigencia de los derechos fundamentales en una sociedad posmoderna
}

\section{Elements for the critical review of the relationship between Criminal Law and the enforcement of fundamental rights in a postmodern societyerna}

https://doi.org/10.15332/iust.v0i15.2088

\begin{abstract}
Arnel Medina Cuenca
Profesor titular de Derecho Penal de la Facultad de Derecho de la Universidad de La Habana (La Habana, Cuba); vicepresidente de la Sociedad Cubana de Ciencias Penales.

Correo electrónico: arnel@lex.uh.cu

María del Rosario Molina González.

Doctora en Derecho; docente e investigadora del Departamento de Ciencias Sociales de la Universidad de Sonora, Unidad Regional Sur; líder de Cuerpo Académico Dogmática Jurídica y Proceso Educativo. Tendencias Actuales (UNISON-CA-165).

Correo electrónico: rmolina@navojoa.uson.mx
\end{abstract}

Angel Fernando Castro Gutiérrez

Abogado por la Universidad Externado de Colombia: maestría en Análisis y Prevención del Crimen por la Universidad Miguel Hernández, Comunidad Valenciana, España; magíster (C) en Derecho área de Profundización en Derecho Penal por la Universidad Nacional de Colombia; especialista en Derecho Penal y Mujeres por la Universidad de Chile; fiscal delegado ante los Jueces Especializados; investigador del grupo de Investigación "Escuela de Derecho Penal "Nullum Crimen Sine Lege UN".

Correo electrónico: afcastrog@unal.edu.co

\begin{abstract}
La dignidad humana y la libertad en el proceso penal están en retirada. Hoy, igual que antes, su alcance no está claro. Ceden a menudo a la funcionalidad de la justicia penal, a la necesidad de seguridad de la población y a su llamado "derecho fundamental a la seguridad". El proceso penal ya no se concibe a sí mismo totalmente Magna Carta para repeler o prevenir peligros para la libertad del afectado, sino que, muchas veces, es un instrumento para neutralizar los peligros para la justicia penal -aún más, para promover la prevención en el sentido de prevención de delitos.
\end{abstract}

Amelung et al. (2005)

\begin{abstract}
Resumen
La superación de un conflicto armado y de un pasado violento en general, desde el lente de la justicia transicional, demanda no solo la judicialización de aquellas conductas delictivas consideradas no sujetas a indulto o amnistía, sino que el resultado de la rendición de cuentas que subyace al ejercicio de la acción penal en la judicialización de crímenes internacionales, debe permitir la revisión crítica de las estructuras del derecho penal ordinario, que de una u otra forma aportaron a la profundización de las causas del conflicto armado.
\end{abstract}

Palabras clave: Derecho penal de transición, justicia transicional, impunidad, función y fin de pena, principio de legalidad, crímenes internacionales, derecho penal de posconflicto, estructuras de legitimidad. 


\section{Abstract}

The overcoming of an armed conflict, and a violent past in general from the lens of transitional justice, demands not only the prosecution of those criminal behaviors considered not subject to pardon or amnesty, but the result of accountability that underlies to the exercise of criminal action in the prosecution of international crimes must permit a critical revision of the structures of ordinary criminal law, which in one way or another contributed to the deepening of the causes of the armed conflict. For this reason, the revision of notions such as impunity, punishment and the guarantees of criminal law and criminal procedure has such importance, as not only the success of the transitional justice exercise depends to a great extent on the operation of the system, but the ordinary criminal law system will be strongly impacted in its categories.

Keywords: Transitional criminal law, transitional justice, impunity, function and purpose of punishment, rule of law, international crimes, criminal law postconflict structures legitimacy.

\section{Résumé}

Le dépassement d'un conflit armé, et d'un passé violent en général du point de vue de la justice transitionnelle, exige non seulement la judiciarisation des conduites criminelles considérées comme non soumises à la grâce ou à l'amnistie, mais le résultat de la responsabilité qui sous-tend L'exercice d'une action pénale dans la poursuite des crimes internationaux devrait permettre une révision critique des structures du droit pénal ordinaire, qui d'une manière ou d'une autre a contribué à l'approfondissement des causes du conflit armé.

Mots clés: Droit pénal transitoire, justice transitionnelle, impunité, fonction et but de la peine, principe de légalité, crimes internationaux, droit pénal post-conflit, structures de légitimité. 


\title{
Elementos para la revisión crítica de la relación entre el derecho penal y la vigencia de los derechos fundamentales en una sociedad posmoderna*
}

\author{
Arnel Medina Cuenca \\ María del Rosario Molina González \\ Ángel Fernando Castro Gutiérrez
}

\section{INTRODUCCIÓN}

La modernidad no es ajena a las constantes tensiones entre las herramientas punitivas y la vigencia de los derechos fundamentales. De hecho, la actualidad se define por la constante lucha entre sistemas abiertamente eficientistas, y las diferentes manifestaciones de resistencia garantista, que desde un constante retorno a los fundamentos del derecho penal liberal buscan denunciar que los procesos de criminalización-incriminación primarios y secundarios, no son en sí mismos producto de ejercicios legislativos tradicionalmente considerados, sino que evidencian relaciones de poder.

- $\quad$ Esto significa, que en la realidad se ha superado por mucho el paradigma restringido del ámbito de regulación penal, para reconocer que a través de proceso de proscripción penal se pueden alcanzar otros tipos de fines y funciones, entre ellos, políticos. Esto es que regula ciertas conductas de forma directa, pero también impacta y transforma en otras direcciones. En este sentido, el presupuesto de fragmentariedad del derecho penal, resulta evidentemente rebatido por procesos expansionistas que impactan dinámicas sociales, profundizan modelos de relacionamiento que lejos de obedecer a dinámicas constitucionales de protección de derechos, en clave de bienes jurídicos, resultan abiertamente discriminatorias y reciclan desde un ámbito hipotético de ejercicio de derechos, la restricción de un conjunto de presupuestos para el goce efectivo de los derechos fundamentales, de la consolidación del modelo democrático y de Estado de derecho.

* Artículo de investigación desarrollado en el marco de la colaboración entre los grupos de Investigación: "Escuela de Derecho Penal Nullum Crimen Sine Lege UN", de la Universidad Nacional de Colombia, reconocido y clasificado en A por Colciencias 2015, y el Cuerpo académico de la Universidad de La Habana y de la Universidad de Sonora, sede Navojoa, México. 
El transcurso de definición del objeto de protección -como finalidad del derecho penal- no ha sido en absoluto pacífico, por el contrario, son incontables los momentos históricos donde la herramienta punitiva ha estado a disposición de modelos totalitaristas, y donde indiscutiblemente se ha instrumentalizado al derecho penal para perseguir entre otros la diferencia mediante su criminalización, y que atraviesa eso que Carlos Santiago Nino llamaría el mal absoluto (Nino, 2006).

De hecho, la historia de las graves violaciones a los derechos humanos, e infracciones al derecho internacional humanitario en el siglo XX y el corto transcurso del XXI, está mediada por intentos de legitimar la barbarie y la arbitrariedad desde el poder jurisdiccional (Huertas, 2011). Testimonio de esta afirmación se encuentra en el juicio de los juristas en el Núremberg de la posguerra, y los juicios de los disparos en el muro, donde el debate atravesó los términos de la responsabilidad penal, para irradiar la discusión de la filosofía del derecho penal, a tal punto que el impacto de tal revisión crítica hoy se siente en la reingeniería de los fundamentos de legitimidad del derecho penal. Uno de los ejemplos donde se testimonia esta afirmación está en la construcción moderna de la noción de bien jurídico y su anclaje indiscutible a criterios de corrección constitucional, incluso extendida a ejercicios de política criminal (Roxin, 2002).

Es allí donde constantemente la legitimidad del sistema penal no es solo puesta en duda, sino que atraviesa momentos de profundas revisiones críticas, que han impactado la totalidad de institutos y categorías dogmáticas, para ser construidas en función de un referente como el bien jurídico, anclado ya no a hondas raíces liberales, sino además a anclajes tales como los derechos fundamentales y un referente constitucional de política criminal, de modo tal que las ignominiosas versiones del derecho penal de los totalitarismos queden por completo proscritas del universo.

En este sentido, de cara a la aparición de una nueva jurisdicción de justicia transicional, resulta fundamental explorar los conceptos que son utilizados para afirmar una visión hegemónica del mundo, y que entren en confrontación con mecanismos de superación negociada de conflictos armados, ya que se afincan en fundamentos maximalistas propios de la herramienta punitiva, o bien como una extensión, o como parte integrante de la estrategia bélica en un conflicto. Esto significa que, de la definición del contenido y alcance de un conjunto de nociones, principios y reglas, se podrá consolidar un modelo de transición que dé paso a un derecho penal de posconflicto que desde su operatividad no vaya a servir de fecundo campo a la reedición de violencias.

Este artículo, lejos de buscar reconstruir históricamente las revisiones críticas del concepto de referencia de impunidad, de bien jurídico con base al referente constitucional, buscará explorar la necesidad de replantear la relación entre los derechos fundamentales y la construcción de las estructuras de legitimidad del sistema penal de posconflicto, de modo tal, que se brinde una aproximación a los elementos discursivos para trazar la relación trasformadora entre un concepto constitucional material de delito, que coadyuve al resto de instrumentos orientados a la superación del conflicto armado, y la consolidación de la paz. 


\section{SUPERACIÓN DEL CONFLICTO, NOCIÓN DE IMPUNIDAD Y COMPROMISO TEÓRICO DE UN CONCEPTO DE JUSTICIA}

La vinculación desde la orilla retribucionista de la justicia y de la teoría de la pena al principio nullum crimen sine poena, es propia del derecho penal autoritario, por oposición al enunciado del derecho penal liberal de nullum crimen sine lege. Esta tensión ha derivado en la exigencia retribucionista, que en términos de Jesús María Silva Sánchez (2008) obliga a que todas las conductas consideradas delictivas deben ser castigadas, incluso si para ese cometido se debe prescindir de la observancia de las garantías formales asociadas al principio de legalidad, entre otros, cuando estas se oponen a la sanción de una conducta que se considera merecedora de pena'.

Este fenómeno que se entendía extinto de la discusión penal ha sufrido una fuerte reedición, que lo ubicado en escenarios que han sido denunciados como de neopunitivismo o poslegalidad (Tokatlian, 2012) ${ }^{2}$ los cuales dentro de las doctrinas de la lucha contra la impunidad, impunidad cero, o el derecho de la víctima al castigo del autor, han ubicado a la evitación de la impunidad como uno de los fines principales de la pena, en ámbitos concretos de desarrollo como los crímenes internaciones, donde a modo de dogma o paradigma, se afirma que sin castigo a todos los crímenes y a todos los criminales no se puede dar trámite a la justicia transicional o la superación del pasado.

Esta demanda maximalista desconoce sustitutos funcionales de la pena privativa de la libertad, enfocándose exclusivamente en el castigo del perpetrador, fundamentándose en un modelo de justicia retributiva que tiene como fundamento el principio de culpabilidad y el libre albedrío del delincuente, siendo el derecho penal una reacción al uso inconveniente de la libertad realizado por un hombre, que ha adoptado por hacer el mal pudiendo hacer el bien (Kant). Esta corriente se basa en que la culpabilidad del victimario solo se compensa con la imposición de una pena, en ese sentido la pena es la retribución del mal causado y por lo tanto la pena es un fin en sí mismo que debe ser proporcional al delito cometido.

Ahora bien, este enfoque se basa en tres supuestos: (i) la comunidad tiene superioridad moral frente al delicuente y por eso el Estado puede imponer la pena;

1 Corte Constitucional Sentencia C-554/01 "En efecto, si bien diferentes pactos y tratados internacionales reconocen la garantía mínima fundamental a no ser juzgado ni sancionado por un hecho punible respecto del cual se ha sido condenado o absuelto de conformidad con la ley -principio cuya efectividad está garantizada por el canon 93 Fundamental-, lo cierto es que la exigencia cada vez más grande de una justicia ecuménica, orientada a reprimir comportamientos que afecten bienes de gran interés y valía para toda la humanidad, ha llevado a los Estados a replantear la inmutabilidad de ciertos axiomas, entre ellos el de la cosa juzgada y, por ende, el del non bis in idem".

2 Juan Gabriel Tokatlian "En ese contexto, la poslegalidad tiende a imponerse: se trata de una situación en la que el derecho interno e internacional se manipula, se desconoce o se quiebra a expensas de un bifronte Estado gendarme que opera con escasa rendición de cuentas hacia adentro y con excesivo despliegue militar hacia afuera. Lo poslegal no es patrimonio exclusivo de Estados Unidos -recientemente la secretaria del Interior de Reino Unido, Theresa May, sugirió la necesidad de deshacerse de la Ley de Derechos Humanos de 1998-, pero tiene su manifestación más elocuente e inquietante en aquel país". 
(ii) la culpabilidad del delincuente puede ser medida según su gravedad; (iii) la sentencia puede ser considerada al haberse armonizado el grado de culpabilidad y la gravedad de la pena (Duran, 2011).

Este referente de construcción de un modelo de justicia resulta no solo inconveniente para el arribo, desde el mecanismo de justicia transicional, al conocimiento de un sinfín de crímenes, sino que además resulta disfuncional a la hora de poder resolver un conflicto armado desde la negociación política (Huertas, 2012), puesto que pone como condicionamiento el cumplimiento de un marco normativo presupuestado para escenarios de normalidad, siendo un conflicto por lo general un escenario de excepcionalidad, donde el Estado de Derecho es abandonado para echar mano de la facticidad para la resolución de un conflicto. Por esta razón, el compromiso teórico de una noción de justicia es el primer paso para resolver el alcance de la utilización del derecho penal en el enjuiciamiento de crímenes cometidos en conflictos armados.

Es así, que la justicia restaurativa surge como un modelo alternativo al derecho penal retributivo, los defensores de este enfoque consideran que el castigo retributivo al ofensor es insuficiente para restablecer la convivencia social. El presupuesto de este enfoque es la importancia que tiene para la sociedad la reconciliación entre víctima y victimario. En ese sentido, busca que el derecho penal deje de concentrarse en el acto criminal y el victimario, para que por el contrario se centre la atención hacia la víctima y el daño que le fue ocasionado.

Desde este enfoque es más importante reconocer el sufrimiento de la víctima, repararle el daño que le fue causado y restaurarla en su dignidad, más que castigar al responsable, a quien debe tratarse de reincorporar a la comunidad a fin de restablecer los lazos sociales, y en particular en escenarios de superación del conflicto armado construir las condiciones para dar el paso a la transición (Uprimny \& Saffon).

Igualmente, la justicia restaurativa busca mecanismos, como la mediación, por medio de los cuales el victimario pueda adquirir conciencia del daño que causó, reconocer su responsabilidad e intentar reparar el daño. Es por ello, que se ha entendido que la justicia restaurativa busca centrarse no en el pasado, si no en el futuro para lograr una convivencia pacífica reconstruyendo lazos sociales (Uprimny \& Saffon).

Del mismo modo, una tercera vía se halla en la justicia transformadora, la cual se edifica en la tendencia que cuando se pretende reparar a una víctima, se debe considerar no sólo la condición en que quedó la victima luego del delito, sino cuál era su condición antes de la violación (Huertas, et al. 2006), en consideración a que sociedades como la colombiana son en sí excluyentes, desiguales e inmersas en conflicto interno; por lo que si se adopta una reparación retribucionista, según el cual se debe dejar a la víctima en la situación que estaba antes de la violación de derechos humanos, termina devolviendo a las víctimas a una situación de vulnerabilidad y carencias.

Lo anterior, por cuanto no se atiende los factores estructurales del conflicto, impidiendo garantizar la no repetición de los hechos y perpetua las injusticias que 
padecen las víctimas. De allí que se proponga las reparaciones transformadoras que buscan no solo a través de la justicia correctiva, sino a través de reparaciones que permitan transformar las sociedades democráticas, a fin de superar las situaciones de exclusión y de desigualdad que pudieron alimentar la crisis humanitaria y la victimización de las poblaciones vulnerables y que resultan contrarias a los principios básicos de justicia (Uprimny \& Saffon, 2009).

\section{REDEFINICIÓN DE LA NOCIÓN TRADICIONAL DE IMPUNIDAD CON REFERENCIA A LOS FINES Y FUNCIONES DE LA PENA}

Partiendo del presupuesto que el derecho penal, y en particular su intervención se define con referencia a la noción de pena, es fundamental precisar que de cara a la implementación de unos acuerdos que acompañan un proceso de paz, la sanción penal debe hallar sus rendimientos funcionales, si bien no en lugares diferentes al derecho penal de tradición liberal, por lo menos en su papel en la del conflicto armado. Eso significa, que la pena y la sanción privativa de la libertad no son sinónimos, ni mucho menos, que el retribucionismo como lectura restringida del derecho a la justicia de la víctima, sea el único papel llamado a cumplir por la pena.

De manera independiente a los ingentes desarrollos en materia de teoría de la pena, el referente normativo que regula la función de la pena en Colombia se encuentra en el artículo 4 de la Ley 599 de 2000, cuyo tenor literal asigna a la sanción penal "las funciones de prevención general, retribución justa, prevención especial, reinserción social y protección al condenado". Este papel históricamente ha sido atribuido a la pena privativa de la libertad como la pena por excelencia, lo que ha generado que la noción de impunidad en sentido estricto se concentre no solo en la inexistencia de responsabilidad penal, sino también en la imposición de una pena, para su posterior incumplimiento.

Esta comprensión tan restringida es completamente disfuncional a los escenarios de superación del conflicto en espacios de negociación, toda vez, que por un lado el fin de las hostilidades no está mediado por una rendición, es decir, no es justicia de vencedores, la cual permite eventualmente que los Estados apliquen de manera categórica su cuerpo normativo al bando vencido, con todas las implicaciones de la legalidad penal y procesal penal. Por otro lado, la pena privativa de la libertad, así como la extensión temporal de esta, por la comisión de diversos tipos de crímenes, incluyendo los internacionales, es disfuncional, no solo a la reincorporación a la vida civil, así como a la reconciliación, ya que por un lado genera un nudo crítico que puede eventualmente afectar el término del conflicto, y por otro, no es funcional a la superación del conflicto, el cual necesita fuertes esfuerzos estatales de reconstrucción social (Huertas, 2015), basada no solo en la imposición de una pena privativa de la libertad.

Ahora bien, esto significa que de cara a aquellos delitos que no pueden ser objeto de amnistías o indultos, como los crímenes internacionales, la persecución penal no 
se puede limitar a la imposición de penas privativas de la libertad, para cumplir con las obligaciones internacionales en la materia. Por el contrario, deben privilegiarse formas de ejecución penal que desplacen el dolor penal a la construcción de la vigencia de los DD.HH. y del DIH. Esto es, desde la revisión del concepto de impunidad penal y de la teoría de la pena, encontrar sustitutos funcionales de pena que lejos de instrumentalizar al procesado, permitan entre otros la reconstrucción de la verdad, la reparación de las víctimas y el aseguramiento de la garantía de no repetición.

De esta forma, con la creación de la Jurisdicción Especial para la $\mathrm{Paz}^{3}$, producto del Acuerdo de Paz suscrito por el Gobierno Nacional y las FARC-EP, la búsqueda de la superación del conflicto armado está acompañada de la creación de mecanismos que permitan dentro de un contexto de justicia transicional ejercer una rendición de cuentas sobre la responsabilidad penal de crímenes internacionales. De esta forma, los instrumentos establecidos por el constituyente secundario hacen referencia a la creación de mecanismos de (i) priorización y selección ${ }^{4}$, (ii) mecanismos no judiciales de investigación y sanción y, (iii) mecanismos que incluya a todas las partes del conflicto.

Estos mecanismos van encaminados a evitar la impunidad y buscar la mejor garantía de los derechos de las víctimas. Así pues, con la priorización se busca que el Estado utilice de manera más eficaz los recursos disponibles y por lo tanto, satisfaga en una mayor medida la expectativa de la sociedad y las víctimas ${ }^{5}$ de saber la verdad sobre los hechos de graves violaciones de derechos humanos ${ }^{6}$. La priorización permite que un crimen no se investigue de manera aislada, sino inserto en un contexto determinado 7 , lo cual posibilita un mejor acceso a la justicia para las víctimas, al otorgar recursos que den respuesta y resultado a las violaciones de derechos ${ }^{8}$.

En lo que respecta a la selección, es claro que sin la posibilidad de establecer mecanismos de selección, los fiscales no podrían concentrarse en los más responsables, al tener que avanzar en todos los casos a la vez, impidiendo el esclarecimiento de

3 Artículo transitorio $5^{\circ}$ del Acto Legislativo 01 del 4 de abril de 2017.

4 En lo que respecta a la selección, el acto legislativo establece que será una ley estatutaria la que determine los criterios de selección para que se realice la investigación sobre los máximos responsables de los crímenes de lesa humanidad, genocidio, o crímenes de guerra cometidos de manera sistemática. De igual manera, es competencia del legislador estatutario establecer unos casos, requisitos y condiciones en los que procederán diversas medidas en relación con aquellos que no sean calificados en términos de "máximos responsables", tales como: (i) la suspensión de la ejecución de la pena; (ii) aplicación de sanciones extrajudiciales; (iii) penas alternativas; (iv) modalidades especiales de ejecución y cumplimiento de la pena; (v) así como autorizar la renuncia condicionada a la persecución judicial penal de todos los casos no seleccionados.

5 Corte IDH. Caso de la Comunidad Moiwana vs. Surinam. Excepciones Preliminares, Fondo, Reparaciones y Costas. Sentencia 15 de junio de 2005. Serie C No. 124. para. 204.

6 Corte IDH. Caso Velásquez Rodríguez vs. Honduras. Fondo. Sentencia de 29 de julio de 1988. Serie C No. 4. para. 181; Corte IDH. Caso Masacres de Río Negro vs. Guatemala. Excepción Preliminar, Fondo, Reparaciones y Costas. Sentencia de 4 de septiembre de 2012 Serie C No. 250. para. 173.

7 Corte IDH. Caso Manuel Cepeda Vargas vs. Colombia. Excepciones Preliminares, Fondo, Reparaciones y Costas. Sentencia de 26 de mayo de 2010. Serie C No. 213. para. 118 y 119.

8 Corte IDH. Caso Maritza Urrutia vs. Guatemala. Fondo, Reparaciones y Costas. Sentencia de 27 de noviembre de 2003. Serie C No. 103. para. 117. 
patrones y contextos y que las víctimas conozcan la verdad. No se trata de otorgar amnistías o indultos, porque los casos que no se persigan penalmente estarán sometidos a procesos no judiciales de investigación y sanción. Ahora bien, varios sectores de la sociedad han señalado que el marco jurídico para la paz lleva a la impunidad, al violar la obligación internacional del Estado de investigar y sancionar todas las violaciones de derechos humanos a través de un proceso penal.

Este enfoque maximalista considera, por un lado, que dicha obligación internacional no está sujeta a ningún tipo de restricción y por lo tanto tiene una estructura de regla que no permite su ponderación. Asimismo, parten de una definición restrictiva de lo que debe entenderse por impunidad, en la cual se requiere juzgar todo por el derecho penal y a través de una pena privativa de la libertad proporcional al delito cometido.

No obstante, el concepto de impunidad es mucho más amplio y no solo considera medidas de carácter penal. De hecho, en el informe final del relator especial sobre impunidad y conjunto de principios para la promoción de los derechos humanos

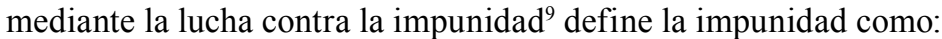

(...) Por impunidad se entiende la inexistencia, de hecho o de derecho, de responsabilidad penal por parte de los autores de violaciones, así como de la responsabilidad civil, administrativa o disciplinaria, porque escapan a toda investigación con miras hacia su inculpación, detención, procesamiento y, en caso de ser reconocidos culpables, condenas a penas apropiadas, incluso a la indemnización del daño causado a sus víctimas (...) (Subrayas fuera de texto).

Dicha definición se encuentra en concordancia con lo establecido por la Corte Interamericana de Derechos Humanos, sobre el alcance de la obligación del deber de investigar y su relación con la obligación del Estado de combatir la impunidad.

\section{DESAFÍOS CONTEMPORÁNEOS EN LA INVESTIGACIÓN DE LOS CRÍMENES INTERNACIONALES. ESPECIAL MENCIÓN A LAS EJECUCIONES EXTRAJUDICIALES EN LÓGICA DE MACROCRIMINALIDAD}

El fenómeno delictivo fue originalmente abordado como el resultado de una acción individual. No obstante, recientes estudios criminológicos registran una evolución de la actividad delictiva orientada a la réplica de los modelos organizativos empresariales en la comisión de los más variados ilícitos, cuyo margen de lesividad se extiende a múltiples bienes jurídicos o expectativas normativas, los cuales se ven impactados gracias al grado de sofisticación organizativa, adoptada por esta forma de macrocriminalidad (Moreno, s.f.). Las ejecuciones extrajudiciales y los demás crímenes internacionales no han sido ajenos a esta suerte de refinamiento en todas

$9 \quad$ Doc. $\mathrm{E} / \mathrm{CN}^{\circ}$ 4/Sub. 2/1997/20/Rev. 1. 
las etapas de planeación y ejecución, de tal forma que su perpetración implica tal como ya se ha afirmado, un planteamiento ampliado de estructuras de imputación orientadas a establecer una responsabilidad penal integral.

Así, la comprensión del fenómeno delictivo de los homicidios cometidos en modalidad de ejecuciones extrajudiciales es una tarea preliminar, exigida para el desarrollo y la evaluación de las acciones concretas de política criminal al respecto (Huertas, et al. 2016), de modo tal, que solo cuando se cuenta con la caracterización de los elementos que intervienen o inciden en la perpetración de este tipo de delito, se tiene margen real de intervención pública y estrategias de acción orientadas a la prevención y combate de este fenómeno esencialmente macrocriminal.

Ahora bien, la importancia de una investigación eficaz para la persecución de estos delitos radica en la inaplazable necesidad de desarticulación de este tipo de aparatos criminales, si se tiene en cuenta, que la misma es uno de los mayores riesgos para la vigencia del Estado de derecho. Igualmente, su eficaz judicialización depende del éxito investigativo que tenga el ente acusador, de forma tal que al ser una prioridad, cualquier modelo que se adopte en relación con la investigación y juzgamiento debe ser puesto en el contexto de una estrategia que trascienda la solución de casos concretos aislados, en concreto, cuando se concentra en develar de la estructura jerárquica al interior de las fuerzas militares, su operatividad y ámbito de actuación.

\section{EXPANSIÓN DEL DERECHO PENAL Y PRIORIDADES POLÍTICO CRIMINALES DE LUCHA CONTRA DE LOS CRÍMENES INTERNACIONALES}

Alrededor de los trabajo de caracterización del estado del arte del derecho penal a finales del siglo XX y principios de siglo XXI, el derecho penal de la globalización, la sociedad de riesgo, derecho penal de enemigo y el expansionismo del derecho penal, entre otros, han sido conceptos comunes, en las diversas explicaciones teóricas, para la redefinición de los fundamentos considerados inmutables propios del Estado de derecho de raigambre liberal.

Estas nociones se han desarrollado de la mano no solo de instituciones penales, procesales penales y criminológicas, sino particularmente de los fenómenos delictivos contemporáneos, tales como la:

criminalidad organizada (narcotráfico, terrorismo, pornografía), la criminalidad de las empresas (delitos fiscales, medioambientales, en materia de consumo -salud e intereses económicos-), la corrupción político-administrativa o el abuso de poder, e incluso la violencia conyugal del denominado "tirano doméstico" y el acoso sexual, aparecen en primer plano de la discusión social sobre lo delictivo (Silva, 2001). 
La criminalidad internacional no es ajena a la revisión crítica por un lado de las instituciones penales, un ejemplo claro se manifiesta en la garantía judicial de legalidad penal y procesal penal, cuyo alcance ha sido flexibilizado, tanto en la experiencia jurídico penal de los Tribunales Internacionales, como en el interior de aquellos países que han tenido que perseguir este tipo de conductas.

Ante esta realidad la herramienta punitiva estatal ha sido en gran medida poco exitosa, en el correspondiente proceso de actualización sistémica, que permite operativamente responder a la manifestación de sentido, que significa el delito. Este presupuesto ha dificultado en gran medida el proceso de revisión crítica del contenido habitualmente atribuido a las categorías dogmáticas, entre otras, porque hoy en día, particularmente la delincuencia de la globalización, en este caso las ejecuciones extrajudiciales, ya no se agota en el paradigma de un hecho constitutivo de un delito cometido por una persona y agotado instantáneamente. De hecho, resulta coherente frente a fenómenos delictivos de alcance transnacional e internacional, seguir hablando de macrocriminalidad organizada (Silva, 2001) ${ }^{10 .}$

Ahora bien, este tipo de macrocriminalidad hace parte de los llamados delitos de organización o relacionados con asociaciones ilícitas, los cuales en lógica del expansionismo penal tienen dos impactos particulares en lógica de derecho penal material. El primero tiene que ver con las agravaciones punitivas previstas para los delitos imputables al grupo organizado, y el segundo, con la imputación del delito de mera pertenencia a la asociación ilícita. Los desarrollos dogmáticos al respecto están fuertemente asociados al desarrollo entre otros de la teoría del derecho penal del enemigo y el discurso penal de la exclusión.

Los delitos de pertenencia a una asociación delictiva ofrecen un escenario especialmente difícil para la definición, entre otros, del impacto que tanto en la parte general, como especial del derecho penal tiene. De hecho, en la persecución de este tipo de criminalidad "solo se puede proponer una definición de organización operativa en el plano de la tipicidad de los delitos de "criminalidad organizada" si previamente se identifica el injusto al que da lugar la existencia de la asociación ilícita en cuanto delito de organización" (Cancio Melia, 2007).

10 “(...) En realidad, es discutible que la macrocriminalidad organizada (paradigmáticamente, el gran narcotráfico, el blanqueo de capitales, el tráfico de armas, etc.) sea, per se, fuente de inseguridad para el ciudadano individual e incluso objeto de la preocupación del mismo. Este, en general, carece de perspectiva sobre la macrocriminalidad, la cual sólo le alcanza de modo muy indirecto como sujeto pasivo. Sin duda, le preocupa más - generándole mayor inseguridad- la criminalidad callejera masificada (más o menos violenta), entre la que se cuenta desde luego la criminalidad patrimonial organizada de pequeña y mediana gravedad. Aunque también es cierto que recibe, a través de los medios de comunicación, los mensajes relativos a la criminalidad organizada y, asimismo, experimenta directamente las consecuencias marginales de dicha macrocriminalidad (el pequeño narcotráfico y la violencia asociada al consumo de drogas, los ajustes de cuentas entre bandas, entre otros muchos). Sea como fuere, la superposición del interés individual en combatir la criminalidad callejera masificada unida al interés estatal en combatir la criminalidad organizada establecen el perfecto caldo de cultivo de la expansión. (...)". 


\section{INJUSTO DE SISTEMA EN CRÍMENES INTERNACIONALES}

Así como los desarrollos teóricos en materia de autoría y participación en el siglo $\mathrm{XX}$ superaron las tradicionales discusiones del concepto restringido o unitario de autor, es el hecho del reconocimiento de la coparticipación criminal, y de cómo extender los linderos de la responsabilidad penal, a personas que a pesar de tener la competencia de impedir el injusto, causalmente y naturalisticamente no causaron el delito.

La trascendencia de la criminalidad internacional a lo largo y ancho del siglo $\mathrm{XX}$, como un hecho jurídico penalmente relevante ha evolucionado de la mano de los avances en materia autoría, participación e intervención delictiva. De hecho, la doctrina penal ha abordado este fenómeno plurisubjetivo en función de la imputación tradicionalmente, desde la autoría mediata, la coautoría y la participación basada en la inducción y cooperación necesaria (Daza, 2007).

Basta recordar en sede de intervención delictiva los ingentes desarrollos teóricos adelantados desde diferentes escuelas, entre los cuales sistémicamente se destaca la teoría de injusto de sistema desarrollada por el profesor Ernst-Joachim Lampe, donde la forma de intervención delictiva coautoría es redefinida por un elemento adicional al clásico planteamiento de una suma de conductas de autores individuales, lo que denomina como injusto de sistema funcionalmente organizado. $\mathrm{Al}$ respecto, afirma que

Dicho sistema crea una 'nueva cualidad' del actuar 'solidario', el cual 'sobrepasa el actuar individual aislado'. Este sistema fundamenta una nueva cualidad del injusto -el injusto del 'sistema'-, el cual sobrepasa el injusto de comportamiento aislado. Y por último, -dicho sistema en el sistema de la retroalimentación - tiene como consecuencia una nueva forma de responsabilidad -la responsabilidad del 'sistema'- la cual, más allá de la responsabilidad por su propio hacer, incluye el comportamiento del otro coautor sistemáticamente vinculado. Por ejemplo, la responsabilidad por la tentativa punible del sistema o por la realización del hecho punible a través del sistema (Silva, 2001) ${ }^{11}$.

\section{HACIA LA TRANSFORMACIÓN DEL PARADIGMA DE LA INVESTIGACIÓN DE LOS DELITOS DE INJUSTO DE SISTEMA}

La lucha contra el fenómeno de delitos de injusto de sistema en sede de persecución penal ha presentado un conjunto de dificultades y obstáculos, asociados, entre otros, al poco margen de adaptabilidad de la respuesta estatal a un fenómeno, que de acuerdo con su naturaleza, operatividad e impacto, ha dejado de ser un hecho aislado, para convertirse en un fenómeno, incluso internacional.

11 “(...) Los coautores en los delitos dolosos forman un sistema a través de la organización de sus relaciones en un "plan conjunto del hecho". Para ello se atribuyen recíprocamente sus roles. El injusto de 
De hecho, actualmente la operatividad de delitos como las ejecuciones extrajudiciales obedecen a un referente de la fungibilidad, en el que la persecución individual de sus miembros, en nada contribuye a la finalidad de desarticular la estructura criminal (inclusive de naturaleza estatal), de neutralizar sus mecanismos de perpetración, entre otros, de encubrimiento, de protección de las víctimas y, finalmente, de la proscripción y erradicación completa de este tipo de prácticas de las operaciones militares.

Por esta razón, las estrategias tradicionales de investigación criminal han probado su incapacidad en la tarea de explicar la existencia, composición, operatividad, entre otros elementos necesarios para la comprensión del fenómeno, y la correspondiente construcción de estrategias de abordaje y lucha de esta modalidad delictiva. En esa lógica, es fundamental adoptar un enfoque y estrategia investigativa diferente a la tradicional que busque y recolecte la evidencia, información o elemento material probatorio relevante para establecer el contexto de perpetración, los patrones, perfiles, así como las modalidades de preparación, ejecución, agotamiento y encubrimiento desplegado por la estructura criminal.

En esta lógica, de manera conexa existen múltiples conductas delictivas como torturas, desapariciones forzadas, desplazamiento forzado, violencia sexual basada en género, entre otros. Estos delitos que son cometidos en lógica de sistema hacen necesario el replanteamiento del paradigma tradicional de investigación, lo que significa, que de una perspectiva retrospectiva propia de la actividad del juzgador, respecto de una conducta delictiva única y agotada en un hecho, se debe reconocer que estamos ante un fenómeno macrocriminal compuesto por diversos autores y partícipes, en diferentes delitos tanto de agotamiento instantáneo, como de ejecución continuada, se debe transitar a un modelo prospectivo de investigación criminal, que comprenda que mientras que el ente acusador persigue una unidad táctica del Ejército Nacional en la Guajira, un Batallón de Contraguerrilla puede estar cometiendo este tipo de crímenes en Antioquia.

Ahora bien, este presupuesto demanda del poder judicial la articulación, entre escenarios judiciales de persecución, con acciones concretas de política pública de lucha contra la impunidad en crímenes internacionales, de modo que, anudadas a las recomendaciones específicas relacionadas con la creación de una mayor capacidad especializada de investigación, la coordinación, asociación y unificación de

este sistema surge en cuanto al menos uno de ellos, conforme a sus rol entra en una relación de injusto con el entorno social. Su relación de injusto se imputa al sistema porque este autor no solo actúa "en sus propios asuntos" sino también como funcionario del sistema. Si se prepara para exteriorizar directamente el plan del hecho, entonces fundamenta el hecho intentado para todo el sistema. Si lleva a cabo el plan del hecho hasta el final, entonces fundamenta el injusto de la ejecución del hecho para todo el sistema. El injusto del sistema se imputa, además, a los miembros particulares, ya que estos son los causantes del sistema y, por ello, tienen que cargar con la responsabilidad sobre esto. (...) El resultado es que el injusto del sistema está delimitado y limitado al injusto impersonal, conforme a roles de sus miembros. Incluso el someterse a uno de los planes preparados constituye un sistema de injusto en coautoría (...)". 
investigaciones y procesos que por su naturaleza compartan, de manera que se eviten esfuerzos investigativos duplicados y la persecución de la estructura se enfoque en la comprensión íntegra del fenómeno macrocriminal.

Finalmente, el condicionamiento de la investigación criminal a las categorías dogmáticas de derecho penal, ha sido causa del estancamiento y fracaso de innumerables investigaciones, toda vez que los fiscales e investigadores presuponen la existencia de tipologías de estructuras criminales estáticas, lo cual contraviene totalmente la realidad evolutiva de este tipo de macrocriminalidad. Esta práctica genera, no solo la incapacidad de imputación cuando la estructura de atribución de responsabilidad no explica los niveles y grados de autoría, participación e intervención delictiva, sino que tampoco permite que las herramientas de actualización operativa del sistema penal actúen diagnosticando las dificultades y obstáculos de persecución.

\section{DIFICULTADES NORMATIVAS ASOCIADAS A LAS ESTRUCTURAS DE IMPUTACIÓN DE CRÍMENES INTERNACIONALES Y DEBIDO PROCESO}

En el capítulo de la historia universal, dedicado exclusivamente al paradigma de la atrocidad (Card, 2006), las conductas que a la postre serían constitutivas de graves violaciones a los derechos humanos e infracciones al derecho internacional humanitario solo hasta el siglo XX encontraron su cenit (Hobsbawm, 1998)12, en episodios históricos rebosantes de barbarie, crueldad y salvajismo, que se extendieron en diferentes conflictos armados nacionales e internacionales, donde el genocidio, la desaparición forzada, la tortura, las ejecuciones extrajudiciales, arbitrarias y sumarias, la violencia sexual basada en género, el desplazamiento forzado, entre otras, cobraron protagonismo dentro y fuera de las hostilidades.

A la par, los ordenamientos jurídicos de nuestros países contaban con insuficientes herramientas de protección efectiva y persecución criminal, originados en el interior de los órganos constitucionales de representación, y sobre quienes recaía la potestad legislativa. En efecto, el reconocimiento de estas conductas como crímenes internacionales encuentra su origen consenso axiológico de la comunidad internacional y el progresivo de repudio no solo a la perpetración de estas conductas, sino la impunidad provista por la ausencia de persecución, juzgamiento y condena de los responsables.

Este proceso ha significado la construcción de instrumentos ${ }^{13}$ generadores de obligaciones internacionales para los Estados, creadoras de deberes de respeto,

12 “(...) La humanidad sobrevivió, pero el gran edificio de la civilización decimonónica se derrumbó entre las llamas de la guerra al hundirse los pilares que lo sustentaban. El siglo XX no puede concebirse disociado de la guerra, siempre presente aun en los momentos en los que no se escuchaba el sonido de las armas y las explosiones de las bombas. (..)”. (p. 30).

13 Entre otros la Declaración Universal de Derechos Humanos, el Pacto Internacional de Derechos Civiles y Políticos, el Pacto Internacional de Derechos Económicos, sociales y culturales, la Declaración sobre la Protección de todas las Personas contra las Desapariciones Forzadas, así como la Convención Americana de Derechos Humanos y Convención Interamericana sobre Desaparición Forzada de Belém do Pará, El Estatuto de Roma de la Corte Penal Internacional entre otros. 
garantía y protección, so pena de responsabilidad internacional. De otra parte, estas obligaciones han establecido espectros de responsabilidad penal individual, tanto a nivel nacional, como internacional, haciéndose sustancial el análisis de la progresiva criminalización de la conducta en ambos escenarios.

Hoy en día, esta propuesta debe obedecer al sistema de integración normativa de protección internacional de derechos humanos (Benítez, 2013), que ha superado el paradigma de la teoría clásica del derecho internacional, edificándose hoy en día desde un sistema universal de protección de los derechos humanos, y un sistema de protección interamericano de derechos humanos que ha ilustrado el proceso interno de persecución de los crímenes internacionales, en concreto las ejecuciones extrajudiciales.

Frente a este escenario, la relación entre la sanción penal como respuesta a este fenómeno de macrocriminalidad y la protección de los derechos humanos y el Derecho Internacional Humanitario, encuentra en la impunidad (Nino, 2006) ${ }^{14}$ provista por el poder judicial doméstico, frente a este tipo de criminalidad su punto de partida. Esta impunidad no solo ha estado referida a las históricas dificultades y obstáculos de persecución de los responsables de estos crímenes, sino por una parte, por los límites jurisdiccionales, normativos, procesales, probatorios, punitivos, entre otros, que entran en colisión con una de las formas tradicionales de manifestación de la soberanía de un Estado, como lo es la jurisdicción universal, y por otra parte, el problema de la legitimidad en todas sus dimensiones, de los tribunales internacionales constituidos para el juzgamiento retroactivo de este tipo de crímenes.

De esta forma, se presenta la superación de la tradición jurídica de persecución de la responsabilidad internacional de un Estado por estas violaciones, para buscar perseguir individualmente a los autores o partícipes, ya no de violación a obligaciones derivadas del derecho internacional, sino por la comisión de delitos internacionales. Diferenciándose de esta forma entre crímenes internacionales -crímenes de lesa humanidad, crímenes de guerra, genocidio y el crimen de agresión- de los ilícitos internacionales (Barbero, 2011) $)^{15}$.

14 “(...) Al estudiar la historia del derecho penal aplicado a las violaciones masivas de derechos humanos lo que vemos generalmente son amnistías o indultos, un ominoso silencio, y la ausencia de acusaciones formales. A lo sumo, juicios y castigos a la gente equivocada o a la gente correcta pero por los actos equivocados. Oficiales de rango inferior que ejecutaron atrocidades son usados como chivos expiatorios para apaciguar el clamor popular, mientras que los funcionarios políticos o militares que dieron las órdenes correspondientes quedan impunes. En algunas ocasiones los líderes son acusados pero por hechos de mucha menor importancia de aquellos por los cuales existe una demanda de justicia, como sucedió recientemente en el juicio de 1992 contra el líder germano-oriental Hoenneker por asesinatos ocurridos cuarenta años antes. (...)" (pp. 4-89).

15 “(...) Será delito de conformidad con las disposiciones penales, e ilícito de conformidad con la normativa del Derecho Internacional Público. Pero la vigencia y aplicación de una normativa no quita la vigencia y aplicación de la otra. Ambas normativas pueden ser aplicadas a la vez. (...) En caso de incumplimiento por parte de los Estados de la normativa internacional que prohíbe el ilícito en cuestión, la responsabilidad emergente estará alcanzada por los mecanismos previstos por la normativa del mismo ámbito internacional que aquella que tipifica las infracciones. Se activará la responsabilidad del Estado ante el Derecho Internacional Público en caso de estar en presencia de un ilícito internacio- 
Ahora bien, en la persecución de estos crímenes, bien por tribunales internacionales, o por tribunales domésticos o mixtos, los juzgadores se han prevalido de herramientas normativas, dogmáticas y jurisprudenciales del derecho penal doméstico para imputar penalmente a los responsables (Guerrero, 2009) ${ }^{16}$. Este ejercicio de integración normativa ha dado como resultado la identificación, caracterización y documentación de dificultades de diferente origen que impide la transpolación pura de los sistemas de imputación domésticos existentes para la judicialización de delitos comunes, ya que el derecho penal internacional como sistema punitivo, busca atribuir la responsabilidad de un crimen internacional, no bastando solamente el reconocimiento de los actos individuales constitutivos de la ejecución material del injusto, sino que de partida, se exige la configuración de un elemento internacional contenido en el contexto de acción macrocriminal (Guerrero, 2009).

En efecto, las diferencias sustanciales no se restringen a la afirmación de que las "estructuras de imputación del derecho penal internacional difieren profundamente de las del derecho penal doméstico" (Guerrero, 2009), sino que también el andamiaje de garantías del derecho penal de naturaleza liberal burgués, producto de la superación del Ancien régime, se agota, cuando se intenta sancionar la comisión de conductas constitutivas de crímenes internacionales.

Diferentes eventos atestiguan esta desestructuración de las tradicionales instituciones del derecho penal burgués, a favor de la construcción de un sistema de derecho penal internacional, de histórico desarrollo pretoriano, y que se ha erigido de cara a la judicialización de crímenes cometidos por estructuras complejas y sistemáticamente organizadas, que implican la superación de un concepto restrictivo de autor, para establecer modelos de imputación, donde la responsabilidad penal supera la ejecución material del ilícito, y debe ser imputada la intervención delictiva de todas aquellas personas que de acuerdo con el contenido y alcance de su rol eran competentes ${ }^{17}$ y garantes de los derechos humanos y del derecho internacional humanitario.

nal. Como principio general de Derecho Internacional, cualquier incumplimiento de un compromiso impone la obligación de reparar. (...) En cambio, en caso de tratarse de un "crimen internacional", lo cual involucra un tipo penal que en cierto modo recepta una grave violación de derechos humanos protegida especialmente, aquí se abre paso a la responsabilidad penal de aquellos individuos que participaron en la violación o que son responsables de la decisión (...)”.

16 “(...) El Derecho Penal Internacional (DPI) moderno que se inicia con el Estatuto de Nuremberg no reconoció expresamente en el Estatuto del Tribunal Militar Internacional las agresiones sexuales. No obstante esta ausencia, los crímenes de violencia sexual fueron acogidos en una cláusula de analogía referida a "otras acciones inhumanas". Delitos como la violación fueron asumidos posteriormente por la ley número 10 del Consejo de Control Aliado. (...) Si bien el cuadro legislativo internacional es abigarrado por las circunstancias de ausencia de tipificación expresa de ciertas conductas, existe un consenso en la doctrina sobre las bondades del tratamiento jurisprudencial que ha permitido avanzar aunque algunas críticas evidencien que se trata de victorias pírricas frente a las necesidades de protección penal de mujeres y niñas en el contexto de conflictos armados. (...)”.

17 “(...) Desde esta perspectiva, el núcleo de la imputación no gira en torno a la pregunta acerca de si el hecho era evitable o cognoscible. Primero hay que determinar si el sujeto era competente para desplegar los deberes de seguridad en el tráfico o de protección frente a determinados bienes jurídicos con respecto a ciertos riesgos, para luego contestar si el suceso era evitable y cognoscible. (...) si una 
De esta forma y de acuerdo con la Corte Constitucional colombiana ${ }^{18}$, el marco de la imputación de crímenes internacionales dependerá del ámbito de competencia defraudado, en este caso por el perpetrador, ya no exclusivamente por acción, sino igualmente por omisión. Esta formulación es más exigente en los términos de la imputación, lo que significa que en la fortaleza de las garantías penales deberá encontrar su correlato, ya que un sistema de imputación, cualquiera que sea, deberá tener estrictamente delimitadas las reglas de atribución de responsabilidad, para no adolecer de las mismas críticas de legitimidad que el derecho penal convencional, cada vez que se replantea el fin y función de la pena estatal.

Los tribunales internacionales para el juzgamiento penal de los autores y participes de este tipo de conductas hallan en los albores del siglo XX, y tras la culminación de la Primera Guerra Mundial, un antecedente importante normativo, está contenido en el Tratado de Versalles, artículos $227^{19}$ a 230, en los cuales se establecía la obligación de juzgar al Kaiser Guillermo II de Alemania por crímenes en contra de la moralidad internacional y de la sacralidad de los tratados. Este primer antecedente conjugado con la búsqueda del juzgamiento de los responsables por la violación de las leyes y las costumbres de la guerra, así como la obligación de Alemania de extraditar a los responsables de esas infracciones, se vio reducida al seguimiento de unas causas irrisorias, frente a la magnitud de 10 millones de muertos en el conflicto.

De esta forma, solo hasta el final de la Segunda Guerra Mundial, el mundo presenció el primer antecedente mundial, donde esta desestructuración se manifiesta, casos que van desde Núremberg, en contra de los criminales de guerra nazis, hasta las reglas establecidas en el Estatuto de Roma de la Corte Penal Internacional.

persona tiene dentro de su ámbito de competencia deberes de seguridad en el tráfico o de protección frente a determinados bienes jurídicos, en el juicio de imputación es totalmente accesorio precisar si los quebrantó mediante una conducta activa - vg. Facilitando el hecho mediante la apertura de la puerta para que ingrese el homicida- o mediante una omisión - vg. no colocando el seguro de la entrada principal. En una grave violación a los derechos fundamentales, la conducta del garante que interviene activamente en la toma de una población, es similar a la de aquel que no presta la seguridad para que los habitantes queden en una absoluta indefensión. En virtud del principio de igualdad, cuando la acción y la omisión son estructural y axiológicamente idénticas, las consecuencias deben ser análogas: Si la conducta activa es ajena al servicio, también deberá serlo el comportamiento omisivo. (...)”. Corte Constitucional. Sentencia C-1184 de 2001.

18 Corte Constitucional. Sentencia C-1184 de 2001.

19 Artículo 27 del Tratado de Versalles: “(...) The Allied and Associated Powers publicly arraign William II of Hohenzollern, formerly German Emperor, for a supreme offence against international morality and the sanctity of treaties. (...) A special tribunal will be constituted to try the accused, thereby assuring him the guarantees essential to the right of defense. It will be composed of five judges, one appointed by each of the following Powers: namely, the United States of America, Great Britain, France, Italy and Japan. (...) In its decision the tribunal will be guided by the highest motives of international policy, with a view to vindicating the solemn [...] obligations of international undertakings and the validity of international morality. It will be its duty to fix the punishment which it considers should be imposed.[...] The Allied and Associated Powers will address a request to the Government of the Netherlands for the surrender to them of the ex- Emperor in order that he may be put on trial. $(\ldots)^{\prime}$. 
En el primero de los casos, ha sido denunciado como justicia de vencedores (Zolo, $2007)^{20}$, y como tribunal expost facto desde su creación ha tenido un conjunto de críticas atinentes a atacar la legitimidad del sistema de atribución de responsabilidad. El primer punto complejo tiene que ver con la competencia (Guerrero, 2006) penal supranacional para la judicialización de los crímenes cometidos en la Segunda Guerra Mundial, la cual no es plenamente superada con la sentencia US VS. Ohlendorf et al, ya que aunque define cuales son para entonces los crímenes contra la humanidad, el establecimiento del debido proceso es precario, ya que las herramientas de defensa en la investigación se reducían a poder responder a los cargos y a ser interrogado en un lenguaje comprensible ${ }^{21}$.

Entre otros reparos, desde el principio de legalidad en todas sus dimensiones sustanciales y procesales, como la aplicación retroactiva de la ley penal, la comprensión del principio de culpabilidad, el concepto y alcance de la intervención delictiva, la expansión de la imputación (responsabilidad por el mando, conspiración y pertenencia a una organización criminal), elementos subjetivos de responsabilidad (mens rea) (Ambos, 2004), entre otros que no solo en estos juicios sino en experiencias posteriores se verán de una u otra forma replicados, y que exigirán no solo desde los estatutos, sino también desde las reglas de procedimiento y prueba, delimitar las reglas de juego en el entramado procesal penal, para que las decisiones resulten no solo atendibles desde la justicia material, sino que el alcance de la responsabilidad penal derivada de la perpetración de este tipo de crímenes.

Estas dificultades para la estructuración de un proceso penal internacional con todas las garantías se extiende, por ejemplo, a los casos de la condena del general Tomoyuki Yamashita por el tribunal Militar para Extremo Oriente, el cual fue fuertemente criticado por que según algunos "las convenciones internacionales no permiten aplicar la responsabilidad penal vicarial y que era absurdo condenar a un acusado por inacción cuando las tropas norteamericanas impidieron que actuara" (Nino, 2006), o del Obersturmbannführer SS Karl Adolf Eichmann en el juicio de Jerusalén, en donde la responsabilidad penal por el hecho de otro es evidente (Roxin, 2000), puesto que el tribunal:

(...) estableció que Eichmann no cometió la mayor parte de estos crímenes directamente sino a través de otros, pero declaro que en el caso de estos crímenes masivos cuán cerca o distante el agente se encuentre de las víctimas no significa nada respecto de su grado de responsabilidad. (...) (Nino, 2006).

Independiente a la estructura de imputación utilizada para edificar la imputación en el caso de Eichmann, se criticó el hecho de haber sido juzgado bajo leyes

20 En este punto cabe resaltar que la posición británica favorecía la ejecución sumaria de los criminales de guerra Nazi.

21 En este punto cabe resaltar que la posición británica favorecía la ejecución sumaria de los criminales de guerra Nazi. 
retroactivas y por un tribunal de vencedores (Arendt, 2003) ${ }^{22}$. Los ejemplos no se agotan aquí, sino que igualmente se presentan ya en los Tribunales Ad-Hoc, como por ejemplo, en el tribunal penal para la antigua Yugoeslavia, donde en los casos Blaskic, Tadic, Delalic, entre otros, se debate ya no la legitimidad de la justicia penal internacional, sino los derechos y garantías en el proceso, como es el caso del derecho a contrainterrogar los testigos de cargo, la igualdad de armas, el derecho del acusado a la asistencia de un intérprete, etc.

De esta forma, el problema radica en si al darle valor sancionatorio al derecho internacional, por ejemplo, al ejercicio de integración típica a través del nullum crime sine iure (Capellà, 2005) ${ }^{23}$, entre otro tipo de aplicaciones normativas retroactivas, etc, como derecho aplicable, demuestra el agotamiento de las garantías del derecho penal liberal de acto. Y si este hecho exige la construcción unas categorías de imputación o de atribución de responsabilidad particulares para los crímenes internacionales, que encuentren de manera correlativa, un espectro reforzado de amparo, consistente en un cuerpo de garantías que doten de una mayor legitimidad la intervención punitiva del derecho internacional, de cara a la imposición de una pena.

La legitimidad de la intervención penal internacional no solo puede estar referida a la motivación formal-sustancial de la sentencia, sino a la edificación de un proceso penal internacional, que analizando las experiencias antecedentes de judicialización de crímenes internacionales, con miras que la persecución nacional, universal y de la Corte Penal Internacional se configure como un escenario de ejercicio de derechos, donde las estructuras de imputación desplegadas, o las categorías dogmáticas utilizadas encuentren en un cuerpo de garantías procesales que desarrollen el debido proceso, un correlato que robustezca el cuerpo de la decisión judicial, y que brinde a la sentencia una motivación legítima que atribuya la responsabilidad penal a los autores y partícipes del crimen internacional, a partir del rediseño del cuerpo de garantías y de los límites de estas en un proceso penal internacional.

Sosteniéndose, que esta relación de doble vía entre el debido proceso penal internacional, y la debida imputación de crímenes internacionales -principio de

22 “(...) Las objeciones formuladas contra el proceso de Eichmann eran de tres distintas clases. En primer lugar, estaban aquellas que fueron formuladas con respecto a los procesos de Nuremberg, y que fueron repetidas con referencia al de Eichmann. Eichmann era juzgado según una ley de carácter retroactivo, y sus juzgadores eran los vencedores. En segundo lugar, estaban las objeciones que únicamente cabía aplicar al tribunal de Jerusalén, por cuanto ponían en tela de juicio su competencia, así como el que no tomara en cuenta el hecho del rapto de Eichmann. Finalmente, y estas eran las más importantes, estaban las objeciones contra la acusación en sí misma, según las cuales Eichmann había cometido crímenes 'contra la humanidad', antes que 'crímenes contra los judíos', por lo que dichas objeciones quedaban a fin de cuentas dirigidas contra la ley que se aplicó a Eichmann. Como es natural, de esta argumentación resulta que el único tribunal competente para juzgar estos delitos era un tribunal internacional. (...)".

23 “(...) Todo ello lleva afirmar al Tribunal que, en Derecho internacional, la formulación clásica del principio de legalidad penal nullum crimen sine lege se articula como nullum crimen sine iure, "lo que permite una interpretación mucho más amplia de las exigencias derivadas de este principio", y que la tipicidad de los crímenes de derecho internacional no esté determinada necesariamente en el orden internacional por su incorporación en textos escritos. (...)". 
legalidad procesal-deber de persecución-tiene la entidad para desestructurar el marco de garantías del derecho penal burgués, teniendo obligatoriamente que rediseñarse a partir del fin y función de la sanción penal como respuesta a las graves violaciones de derechos humanos, infracciones del derecho internacional humanitario.

\section{CONCLUSIONES}

La implementación del novedoso sistema de justicia transicional, que próximamente empezará a hacer parte del panorama constitucional, presenta un conjunto de retos y tensiones frente a su adecuación a la realidad social, política y legal actuales. Las normas y el marco constitucional y legal vigente, y en particular, los regímenes de derecho penal ordinario, se ven sujetos a confrontaciones con este nuevo régimen de derecho penal ordinario. Esta situación lejos de representar un fenómeno característico propio de un momento histórico de transición, lleva tras de sí múltiples efectos que pueden entorpecer la consecución de los fines constitucionales de la construcción de la paz y la consolidación del modelo de Estado de Derecho.

Estas tensiones demandan un ejercicio hermenéutico que supere la exégesis de la aplicación de las disposiciones con estructura de regla (categóricas y de aplicación disyuntiva) (Arango, 2008), para entenderse a partir de una dinámica constitucional cercana a los principios que optimice la totalidad del sistema de justicia penal en función a la consecución de un conjunto de derechos, como presupuesto de la superación de un conflicto armado, sin llegar a instrumentalizar los derechos y garantías fundamentales, con la excusa de la demanda social de justicia material.

Por esa razón, el modelo de justicia transicional pactado, parte del reconocimiento de principios con relevancia preponderante frente a otros que cederán protagonismo en la búsqueda de un fin constitucional mayor: el derecho a la paz. De hecho, Este ejercicio de ponderación implica una relectura de los fundamentos del derecho penal, en sede de la noción de impunidad, privilegiando una interpretación comprometida con un concepto de justicia transformadora.

En materia del principio de legalidad, debe buscarse una lectura garantista y sólida que robustezca las estructuras de legitimidad del derecho penal, y de esa forma la arbitrariedad sea proscrita de cualquier escenario de atribución de responsabilidad.

Finalmente, la alternatividad penal propia de modelos de justicia de transición debe inspirar la revisión crítica de la pena privativa de la libertad como paradigma de la sanción penal, y de paso a una estrategia integral de lucha contra el delito que a partir de la dignidad humana edifique una respuesta integradora. 


\section{REFERENCIAS}

Ambos, K. (2004). Estudios de Derecho Penal Internacional. Caracas: Universidad Andrés Bello.

Ambos, K., \& Montealegre, E. (2005). Constitución y Sistema Acusatorio. Bogotá: Universidad Externado de Colombia.

Arango, R. (2008). La Ponderación y la Ley de Justicia y Paz. En E. Montealegre Lynett. La ponderación en el derecho (pp. 187-205). Bogotá, Colombia: Universidad Externado de Colombia.

Arendt, H. (2003). Eichmann en Jerusalén. Barcelona: Editorial Lumen.

Barbero, N. (2011). Crímenes de Lesa Humanidad. Especial referencia a las agresiones sexuales. Papeles de ICLA III, 37-65. Recuperado de http://www.nrc.org.co/ images/documentos-internos/Papeles-ICLA-3.pdf

Benítez, C. (2013). México - Colombia: dos décadas de distancia del nuevo constitucionalismo latinoamericano. Revista Derecho y Sociedad, 6, 165-182.

Cancio, M. (2007). El injusto de los delitos de organización: Peligro y significado. En A.L. Callegari. Política criminal e democracia (pp. 149-198). Río de Janeiro, Brasil: Editora Lumen Juris.

Capellà, M. (2005). Los crimenes contra la humanidad en el caso Scilingo. Revista Electrónica de Estaudios Internacionales, 1-13. Recuperado de https://dialnet. unirioja.es/descarga/articulo/1302915.pdf.

Card, C. (2006). El paradigma de la atrocidad: Una teoría del mal. En C. de Gamboa Tapias. Justicia transicional: teoría y praxis (pp. 16-55). Bogotá, Colombia: Universidad del Rosario. Recuperado de https://books.google.com. co/books?id=0oYQpI7BhvwC\&pg=PA16\&lpg=PA16\&dq=paradigma +de+la+atrocidad:+Una+teor\%C3\%ADa+del+mal.+En:+justicia+transicional\&source $=$ bl\&ots $=$ vhMNMBVZnK\&sig=RTyvmF_dzadBnI_S_3g8UsVh5_I\&hl=es\&sa=X\&ved=0ahUKEwjysrmws-3TAhUESCYKHW5SC88Q6A

Daza, C. (2007). Autoría y participación en la delincuencia organizada. En A.L. Callegari. Política criminal Estado e democracia (pp. 23-89). Río de Janeiro, Brasil: Editora Lumen Juris.

Duran, M. (2011). Teorías absolutas de la pena: origen y fundamentos, conceptos y críticas fundamentales a la teoría de la retribución moral de Inmanuel Kant a propósito del neo-retribusionismo y del neo-proporcionalismo en el derecho penal actual. Revista de Filosofia, 67. Recuperado de $<$ http://www.scielo.cl/scielo. php?script $=$ sci_arttext\&pid=s0718-43602011000100009\&lng=es\&nrm=iso $>$. issn 0718-4360. http://dx.doi.org/10.4067/s0718-43602011000100009

Guerrero, Ó.J. (2006). Garantías y debido proceso en el derecho penal internacional. Bogotá: Insituto de Estudios del Ministerio Público.

Guerrero, O.J. (2009). Evolución jurisprudencial del Derecho Penal Internacional en caso de agresiones sexuales. Papeles ICLA I, 1-28. Recuperado de http://www. nrc.org.co/images/documentos-internos/Papeles-ICLA-1.pdf 
Hobsbawm, E. (1998). Historia del siglo XX. Buenos Aires, Argentina: Crítica Grijalbo Mondadori Buenos Aires. Recuperado de https://uhphistoria.files.wordpress. com/2011/02/hobsbawn-historia-del-siglo-xx.pdf

Huertas, O. (2011). Jurisprudencia penal internacional aplicable a Colombia. Logos Ciencia \& Tecnología, 240-242.

Huertas, O. (2012). Organización gubernamental, dificultades y resultados de la Ley 1448 de 2011 (Ley de Restitución de Tierras). Diálogos de Saberes, 69-77.

Huertas, O. (2015). Sistema penal y hacimiento carcelario. Análisis al estado de cosas inconstitucionales en las prisiones colombianas. Revista Jurídica Derecho, 1524.

Huertas, O., Medina, R., Chacón, N., \& Cáceres, V.M. (2006). El derecho a la reparación para las víctimas de violaciones a los derechos humanos. (I. U. Consultores Abogados, Ed.). Elementos de Juicio Revista de Temas Constitucionales, (3), 157-184.

Huertas, O., Manrique, F.E., Correa de M., C., Trujillo, J.S., \& Herreño, D. (2016). Retos para lograr en México la cultura de la paz y los derechos humanos. IUSTITIA, 13, 285-310.

Moreno, R. (s.f.). Archivo Facultad de Derecho UNAM. (U. A. México, Ed.). Recuperado el 12 de mayo de 2017, de https://archivos.juridicas.unam.mx/www/bjv/ libros/1/213/11.pdf

Nino, C. (2006). Juicio al mal absoluto. Madrid: Editorial Ariel.

Roxin, C. (2000). Autoría y dominio del hecho en el derecho penal. Madrid: Marcial Pons.

Roxin, C. (2002). Politica criminal y Sistema de Derecho Penal. Buenos Aires: Editorial Hamurabi.

Silva, J. (2008). ¿Nullum crimen sine poena? Sobre las doctrinas penales de la "lucha contra la impunidad" y del "derecho de la víctima al castigo del autor. Revista de Derecho Penal y Criminologia, 29(86-87), 149-171. Recuperado de http:// revistas.uexternado.edu.co/index.php/derpen/article/view/621/586

Silva, J.M. (2001). La expanción del derecho penal. Madrid, España: Editorial Civitas.

Tokatlian, J. (2012, enero 2). El ocaso demócratico. El País. Recuperado de http:// elpais.com/diario/2012/01/02/opinion/1325458804_850215.html

Uprimny, R., \& Saffon, M. (2009). Reparaciones transformadoras, justicia distributiva y prfundización demócratica. En Reparar en Colombia: los dilemas en contextos de conflicto (pp. 31-71). Bogotá: Centro Internacional para la Justicia Transicional (ICTJ) y Centro de Estudios de Derecho, Justicia y Sociedad (DeJuSticia). Recuperado de http://www.corteidh.or.cr/tablas/r25595.pdf

Uprimny, R., \& Saffon, M. (s.f.). Satellitechnologies. Recuperado de http://www.satellitechnologies.com/USB/lecturas/ru_justiciaRestaurativa.pdf

Zolo, D. (2007). Justicia de los vencedores. De Nuremberg a Bagdag. Buenos Aires: Editorial Trotta. 